\title{
Denizli bölgesinde baş-boyun tümörlerinin dağılımı ve klinik kaynak kullanımına etkisi
}

\author{
The distribution of head and neck tumors in Denizli region and its effects on usage of \\ clinic resources
}

\author{
Aslınur Ezber, Melike Köroğlu, Gizem Yıldız, Fazıl Necdet Ardıç
}

Özet

Amaç: Bölgemizde baş boyun tümörü olan hastaların sıklığını, cinsiyet ve yaşa göre dağılımlarını saptamak, Denizli iline başka illerden gelen hastaların miktarını öğrenmek ve bu hasta grubunun hastanemizde yatak kullanım oranlarına etkisini araştırarak gelecek yatırım planları için veri toplamaktır.

Gereç ve yöntem: 2007-2017 yılları arasında başvurup baş boyun bölgesinde tümör tanısı konulan ve takipleri Kulak Burun Boğaz Hastalıkları Anabilim Dalı'nda yapılan 1635 hastanın kayıtları retrospektif olarak incelenmiştir. Hastalar yaş, cinsiyet, yaşadıkları şehir, primer tümörün yeri ve yatış sürelerine göre sınıflandırımıştır. Tümör tanımları ICD-10 kod sistemine göre yapılmıştır. Bazı kodlar ulusal ve uluslararası istatistiklerle karşılaştırılabilmesi amacıyla birleştirilmiştir.

Bulgular: 2007-2017 yılları arasında Pamukkale Üniversitesi Tıp Fakültesi Hastanesine başvuran 1635 hastanın 358'i kadın 1277'si erkektir. Baş-Boyun tümörü olarak tedavi edilen hastaların büyük çoğunluğuna malign (1341) tümör tanısı konmuştur. Bölgemizde birinci sıklıkta larenks tümörleri görülmektedir. Bunu major tükrük bezi tümörleri izlemektedir.

Sonuç: Bu çalışmada Denizli bölgesindeki baş boyun tümörlerinin önemli bir kısmının durumu tespit edilmiş ve Kulak Burun Boğaz Anabilim Dalı'nın yatak ve işgücü açısından kaynaklarının \%25'inin bu hastalar için kullanıldığı görülmüştür.

Anahtar kelimeler: Baş-boyun tümörleri, epidemiyoloji, sağlık ekonomisi.

Ezber A, Köroğlu M, Yıldız G, Fazıl Necdet Ardıç FN. Denizli bölgesinde baş-boyun tümörlerinin dağılımı ve klinik kaynak kullanımına etkisi. Pam Tıp Derg 2020;13:53-59.

\begin{abstract}
Purpose: The study aims to define the distribution of head neck tumors according to age and gender, to learn the number of patients living in cities other than Denizli, to investigate the effect of these patients on hospital stays and to collect data for future health investment plans.

Materials and methods: The records of the patients who were diagnosed as head and neck tumor and followed by the Otolaryngology department between 2007-2017 were investigated retrospectively. The patients were classified by age, gender, hometown, primary tumor, number of hospital stays. ICD 10 codes were used to classify the tumors. Some of them were combined to compare with national and international statistics.

Results: 1635 Patients (1277 males and 358 females) were diagnosed as head and heck tumors between 2007-2017 in Pamukkale University Hospital. Most of them have malign tumor (1341). The most frequent tumor site in our region was larynx and followed by salivary glands.

Conclusion: We determined the situation of a significant number of head and neck tumors in Denizli region and calculated that the Otolaryngology department used $25 \%$ of its human and bed resources for these patients.
\end{abstract}

Key words: Head and neck tumors, epidemiology, health economics.

Ezber A, Koroğlu M, Yıldız G, Fazıl Necdet Ardıc FN. The distribution of head and neck tumors in Denizli region and Its effec on usage of clinic resources Pam Med J 2020;13:53-59.

\footnotetext{
Aslınur Ezber, Stajyer Dr. Pamukkale Üniversitesi Tıp Fakültesi, Kulak Burun Boğaz Anabilim Dalı, e-posta: aezber15@posta.pau.edu.tr (orcid.org/0000-0001-6238-2751)

Melike Köroğlu, Stajyer Dr. Pamukkale Üniversitesi Tıp Fakültesi, Kulak Burun Boğaz Anabilim Dalı, e-posta: mkoroglu15@hotmail.com (orcid.org/0000-0002-9194-5899)

Gizem Yıldız, Stajyer Dr. Pamukkale Üniversitesi Tıp Fakültesi, Kulak Burun Boğaz Anabilim Dalı, e-posta: gizemyildiz8566@gmail.com (orcid.org/0000-0002-3255-8338)

Fazıl Necdet Ardıç, Prof. Dr. Pamukkale Üniversitesi Tıp Fakültesi, Kulak Burun Boğaz Anabilim Dalı, e-posta: fnardic@pau.edu.tr (orcid. org/0000-0003-4230-3141) (Sorumlu Yazar)
} 


\section{Giriş}

Insanın sağlıklı bir yaşam sürmesi, hem sosyokültürel çevresi ile ilişkileri hem de çalışma hayatındaki devamlılığı açısından önemlidir. Kanser insan yaşamında önemli bir risk faktörüdür. Dünyada her yıl 18.000 .000 yeni kanser hastasına tanı konmakta ve 9,5 milyon kanser hastası da ölmektedir. Ekonomik olarak gelişmiş ülkelerde kanser en önemli ölüm nedenidir. Bu hastaların \%4,9'unu baş boyun kanserleri oluşturmaktadır [1]. Dünyada kanser görülme hızı non-melanoma deri tümörleri hariç erkeklerde ortalama 100.000 de 204, kadınlarda 100.000 de 175 olarak hesaplanmıştır [2]. Bu oranlar ülkemizde 2014 verilerine göre erkeklerde 220 ve kadınlarda 156'dır [3].

Oral kavite, tükrük bezleri, burun ve paranazal sinüsler, farenks ve larenks tümörleri, baş-boyun tümörleri olarak sınıflandırılmaktadır. Baş-boyun kanserleri birçok faktörün etkisiyle oluşan, farklı ülkelerde farklı oranlarda gözlenebilen malignitelerdir. Tütün ve alkol kullanımı, cinsiyet, yaş, ırk, meslek, genetik yatkınlık, beslenme bozukluğu, radyasyona maruziyeti, kötü ağız hijyeni, kronik enfeksiyonlar, travma ve immün sistem bozuklukları önemli risk faktörleridir [4]. İnsidansı, morbidite ve mortalitesi açısından diğer tümörlere göre daha alt sıralarda yer alsa da yerleşim yerine göre anatomik ve işlevsel olarak önemli etkiler oluşturmakta ve hastanın yaşam kalitesinin önemli oranda düşürmektedirler.

Kanser hastaları bireysel olarak maddi ve manevi bir yaşam mücadelesi verirken, hem tedavi olanakları hem de ekonomik harcamalar açısından toplumun ortak kaynaklarına intiyaç duyar. Bu kaynakların planlaması merkezi otoritenin görevidir. Bu yüzden ülke çapında ve bölgesel istatistiklere intiyaç vardır. Ülkemizde 1983 yılından beri ülke çapında kanser kayıtlarının düzenli tutulması için uğraşılmaktadır. İlk aktif kayıt merkezi 1992 yılında İzmir'de kurulmuştur ve kayıt merkezlerinin sayısı artarak devam etmektedir [3].

Son 15 yılda sağlık sisteminin işleyişi değişmiştir. Kanser gibi tedavisi zor, uzun soluklu takip gerektiren ve sağlık sisteminde yük oluşturan hastalıklar belli merkezlerde toplanma eğilimine girmiştir. Denizli bölgesinde ortaya çıkan baş boyun kanserlerinin çok büyük bir bölümü, tanı başka hastanede konmuş veya tedaviye başka bir ilde başlanmış olsa dahi eninde sonunda Pamukkale Üniversitesi Kulak Burun Boğaz Anabilim Dalı'nda kayıt altına girmektedir. Bu yüzden bu klinikten alınacak verilerin önemli ölçüde Denizli bölgesini yansıtacağı düşünülmüştür.

$\mathrm{Bu}$ çalışmada amacımız, bölgemizde baş boyun tümörü olan hastaların sıklığını, cinsiyet ve yaşa göre dağılımlarını saptamak, Denizli iline başka illerden gelen hastaların miktarını öğrenmek ve bu hasta grubunun hastanemizde yatak kullanım oranlarına etkisini araştırarak gelecek yatırım planlarına yardımcı olmaktır.

\section{Gereç ve yöntem}

$\mathrm{Bu}$ çalışma Pamukkale Üniversitesi Tıp Fakültesi Hastanesi elektronik kayıtları üzerinde retrospektif olarak yapılmıştır. Etik kurul izni Pamukkale Üniversitesi Girişimsel Olmayan Klinik Çalışmalar Etik Kurul'undan alınmıştır (60116787-020/45983).

Hastanemize 2007-2017 yılları arasında başvurup Baş Boyun bölgesinde tümör tanısı konulan ve takipleri Kulak Burun Boğaz Hastalıkları Anabilim Dalı'nda yapılan 1635 hastanın kayıtları incelenmiştir. Hastalar yaş, cinsiyet, yaşadıkları şehir, primer tümörün yeri ve yatış sürelerine göre sınıflandırılmıştır. Tümör tanımları ICD-10 kod sistemine göre yapılmıştır. Bazı kodlar ulusal ve uluslararası istatistiklerle karşılaştırılabilmesi amacıyla birleştirilmiştir (Burun ve paranazal sinüs; ağız ve damak ve farenks gibi)

Bütün parametrik değerlerin ortalaması ve standart sapması tablolar halinde düzenlenmiştir.

\section{Bulgular}

2007-2017 yılları arasında Pamukkale Üniversitesi Tıp Fakültesi Hastanesi'ne başvuran 1635 hastanın 358'i kadın 1277'si erkektir. Hastaların yaş ortalaması 61,2 dir (291). Hastaların $\% 73$ 'ünün Denizli'den, $\% 15$ 'inin komşu illerden, \%12'sinin daha uzak şehirlerden geldiği gözlendi (Şekil 1).

Hastaların dermografik verilere göre dağılımı Tablo 1'de özetlenmiştir. Kadınlarda en sık majör tükrük bezi tümörü, erkeklerde en sık larenks tümörü görülmüştür. En yükek yaş ortalaması tonsil tümöründe görülürken 


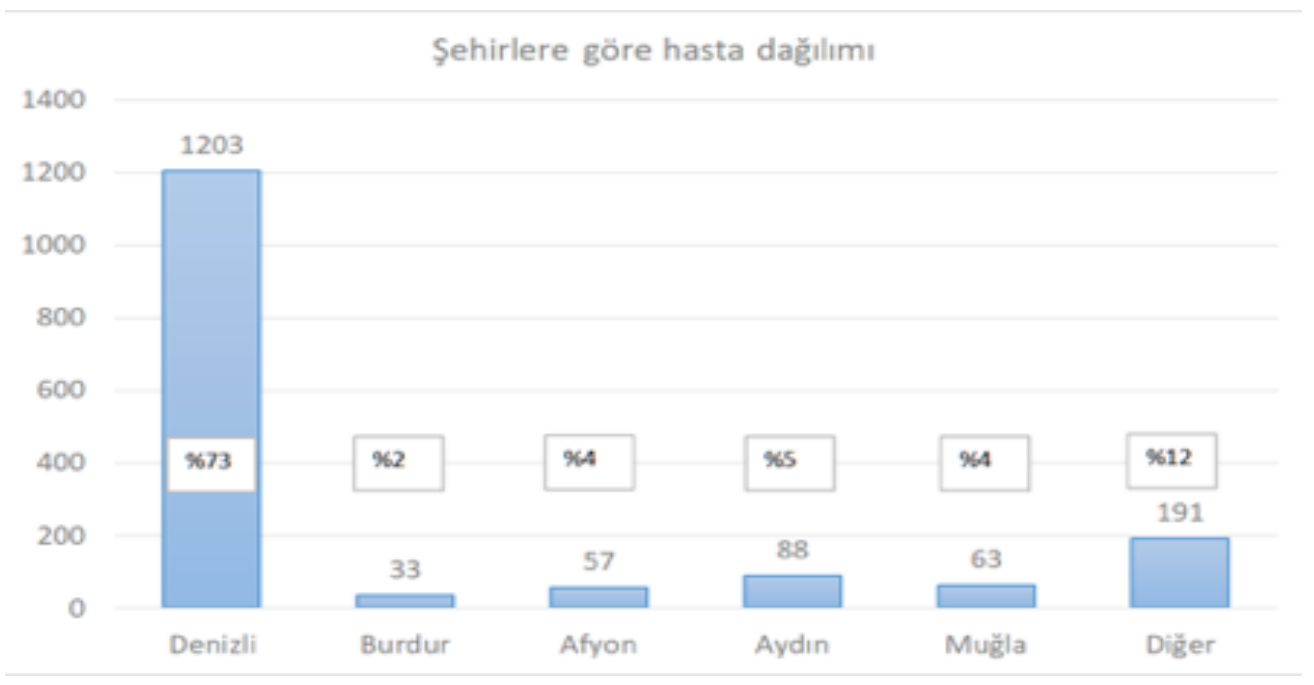

Şekil 1. Hastaların yaşadıkları il sınırlarına göre dağııımı grafikte gösterilmiştir.

Tablo 1. Hastaların dermografik verilerinin dağııımı.

\begin{tabular}{|c|c|c|c|}
\hline Primer & $\mathbf{n}$ & Cinsiyet & Ortalama \pm Std(Min-Max) yaş \\
\hline Paranazal sinüsler & 47 & $21 \mathrm{~K} 26 \mathrm{E}$ & $62,9 \pm 10,2(45-86)$ \\
\hline Ağız, Damak ve farenks & 98 & $39 \mathrm{~K} 59 \mathrm{E}$ & $50,8 \pm 21,0(10-86)$ \\
\hline Paratroid bez & 12 & $6 \mathrm{~K} 6 \mathrm{E}$ & $40,2 \pm 15,3(9-58)$ \\
\hline Kranial komşuluklar & 12 & $4 \mathrm{~K} 8 \mathrm{E}$ & $41,4 \pm 27,9(5-78)$ \\
\hline Deri & 30 & $7 \mathrm{~K} 23 \mathrm{E}$ & $66,8 \pm 14,2(38-93)$ \\
\hline Dil ve Dil kökü & 83 & $35 \mathrm{~K} 48 \mathrm{E}$ & $62 \pm 21(38-91)$ \\
\hline Dudak & 30 & 7K 23E & $63,9 \pm 15,1(39-89)$ \\
\hline Hipofarenks & 6 & $4 \mathrm{~K} 2 \mathrm{E}$ & $62,3 \pm 10,7(46-72)$ \\
\hline Larenks & 749 & $43 \mathrm{~K} 706 \mathrm{E}$ & $65,03(20-91)$ \\
\hline Lenf nodları & 64 & $16 \mathrm{~K} 48 \mathrm{E}$ & $60,76 \pm 13,6(26-90)$ \\
\hline Major tükrük bezleri & 209 & $84 \mathrm{~K} 125 \mathrm{E}$ & $55,7 \pm 18.4(11-90)$ \\
\hline Nazofarenks & 32 & 15K 17E & $59,56 \pm 14,2(22-86)$ \\
\hline Özefagus & 2 & $1 \mathrm{~K} 1 \mathrm{E}$ & $59 \pm 0$ \\
\hline Tonsil & 25 & $10 \mathrm{~K} 15 \mathrm{E}$ & $67,6 \pm 15,03(33-91)$ \\
\hline Diğer ve sınırları belirsiz yerler & 52 & $17 \mathrm{~K} 35 \mathrm{E}$ & $64,79 \pm 13,05(34-87)$ \\
\hline Lipomatöz & 9 & $3 \mathrm{~K} 6 \mathrm{E}$ & $59,6 \pm 14,4(38-78)$ \\
\hline Orta kulak0 & 28 & $10 \mathrm{~K} 18 \mathrm{E}$ & $60,8 \pm 15,2(23-88)$ \\
\hline Bağ dokusu ve yumusak doku & 89 & $32 \mathrm{~K} 57 \mathrm{E}$ & $50 \pm 21,1(6-88)$ \\
\hline \multicolumn{4}{|l|}{ Uzak Metastaz } \\
\hline Over & 2 & $2 \mathrm{~K} \mathrm{OE}$ & $40 \pm 4,2(37-43)$ \\
\hline Meme & 10 & $10 \mathrm{~K} \mathrm{OE}$ & $63,7 \pm 8,2(47-75)$ \\
\hline Mide & 5 & OK 5E & $58 \pm 9,8(47-73)$ \\
\hline Kolon & 2 & $1 \mathrm{~K} 1 \mathrm{E}$ & $67 \pm 1(66-68)$ \\
\hline Kemik ve eklem kıkırdağı & 14 & $8 \mathrm{~K} 6 \mathrm{E}$ & $55,5 \pm 25,6(2-85)$ \\
\hline Bronş ve akciğer & 19 & $5 \mathrm{~K}$ 14E & $62,2 \pm 10,8(48-79)$ \\
\hline Prostat & 3 & $4 \mathrm{E}$ & $73 \pm 8,7(62-80)$ \\
\hline
\end{tabular}


$(67,6 \pm 15,03)$, en düşük yaş ortalaması paratroid tümörlerinde $(40,2 \pm 15,3)$ saptanmıştır. Primer tümörler içerisinde lenf nodları, dil/dil kökü ve ösafagus en uzun yatış süresine sahiptir (Tablo 2). Boyuna metastaz yapan tümörler içerisinde ise Prostat ve Mide tümörleri en uzun yatışa sahiptir. Baş-Boyun tümörü olarak tedavi edilen hastaların büyük çoğunluğuna malign (1341) tümör tanısı konmuştur.
Bölgemizde birinci sıklıkta larenks tümörleri görülmektedir. Bunu major tükrük bezi tümörleri izlemektedir (Tablo 3). Larenks tümörlerinin tamamı malignken, tükrük bezi tümörlerinin çoğunluğunun benign karakterde olduğu görülmüştür.

Tablo 2. Hastaların ortalama yatış süreleri ve tanıları arasında ilişki.

\begin{tabular}{|c|c|c|c|c|}
\hline Primer & $\mathbf{n}$ & Yatış gün & Malign & Benign \\
\hline Lenf nodları & 64 & 16,7 & 64 & 0 \\
\hline Dil ve Dil kökü & 82 & 11,75 & 83 & 0 \\
\hline Ösefagus & 2 & 12,45 & 2 & 0 \\
\hline Larenks & 748 & 11,4 & 749 & 0 \\
\hline Dudak & 30 & 10,2 & 30 & 0 \\
\hline Deri & 30 & 9,6 & 30 & 0 \\
\hline Hipofarenks & 6 & 9 & 6 & 0 \\
\hline Nazofarenks & 32 & 8,8 & 32 & 0 \\
\hline Burun ve Paranazal sinüsler & 47 & 6,7 & 47 & 0 \\
\hline Tonsil & 25 & 7,5 & 25 & 0 \\
\hline Ağız, damak ve farenks & 98 & 8,1 & 55 & 43 \\
\hline Major tükrük bezleri & 209 & 4,9 & 80 & 129 \\
\hline Bağ dokusu ve yumusak doku & 89 & 4,2 & 25 & 64 \\
\hline Paratroid bez & 12 & 3,9 & 0 & 12 \\
\hline Orta kulak & 28 & 5,7 & - & 28 \\
\hline Diğer ve sınırları belirsiz yerler & 52 & 10 & 52 & 0 \\
\hline Kraniyal komşuluklar & 12 & 11,4 & 12 & 0 \\
\hline Lipomatöz & 9 & 3,8 & 0 & 9 \\
\hline \multicolumn{5}{|l|}{ Uzak Metastaz } \\
\hline Prostat & 4 & 15,8 & 4 & 0 \\
\hline Mide & 5 & 14,1 & 5 & 0 \\
\hline Kemik ve eklem kıkırdağı & 14 & 9,7 & 9 & 5 \\
\hline Kolon & 2 & 6,4 & 2 & 0 \\
\hline Meme & 10 & 4,1 & 10 & 0 \\
\hline Bronş ve akciğer & 19 & 3,8 & 19 & 0 \\
\hline Over & 2 & 1,75 & 2 & 0 \\
\hline
\end{tabular}


Tablo 3. Cinsiyete göre tümörlerin görülme sıklığı.

\begin{tabular}{lll}
\hline & Erkek & Kadın \\
& Primer & Primer \\
\hline 1 & Larenks & Major tükrük bezleri \\
2 & Major tükrük bezleri & Larenks \\
3 & Ağız, Damak ve farenks & Ağız, Damak ve farenks \\
4 & Bağ dokusu ve yumusak doku & Dil ve Dil kökü \\
5 & Dil ve Dil kökü & Bağ dokusu ve yumusak doku \\
6 & Lenf nodları & Paranazal sinüsler \\
7 & Diğer ve sınırları belirsiz yerler & Diğer ve sınırları belirsiz yerler \\
8 & Paranazal sinüsler & Lenf nodları \\
9 & Deri & Nazofarenks \\
10 & Dudak & \\
& Uzak Metastaz & Uzak Metastaz \\
1 & Bronş ve akciğer & Meme \\
2 & Prostat & Kemik ve eklem kıkırdağı \\
3 & Kemik ve eklem kıkırdağı & Bronş ve akciğer \\
4 & Mide & Over \\
5 & Kolon & \\
\hline
\end{tabular}

Uzak metastaz olarak primer tümörün baş-boyun bölgesine yaptığı metastaz kastedilmektedir.

\section{Tartışma}

2007-2017 yıllları arasında 1635 hasta baş boyun tümörü nedeniyle tedavi edilmiştir. Bunların 1343 tanesi malign tümördür. Bizim kliniğimizde en sık görülen tümör larenksin malign tümörüdür. Hastalarımızın \%73'ü Denizli ve ilçelerinden başvururken, \%15'i komşu illerden, \%12'si ise daha uzak bölgelerden gelmektedir.

İstanbul'da en sık görülen tümörler arasında ilk sırayı deri (melanom dışı) tümörleri almıştır. Larenks tümörleri 2. sırada yer almaktadır [5]. Sırasıyla tiroid, dudak ve nazofarenks takip etmektedir. Kadınlarda ise sırasıyla tiroid, deri, dudak, nazofarenks ve göz en sık görülen tümörler olarak tespit edilmiştir. Denizli bölgesindeki kadın ve erkeklerde görülen tümörlerin sıklık sırası Tablo 3'de gösterilmiştir. Larenks tümörleri erkek/kadın oranı İstanbul'da 25,2 bulunmuştur, bizde ise bu oran 16,4'tür. Toplam baş boyun tümörlerinde erkek/kadın oranı 1,03 iken bizim çalışmamızda bu oran 3,37'dir [5]. Deri ve troid tümörlerinde oluşan bu farklıı̆ın nedeni İstanbul çalışmasının patoloji merkezli, bizim çalışmamızın Kulak Burun Boğaz merkezli yapılmış olmasıdır. Diğer kliniklere primer tedavi için başvuran özellikle deri ve troid tümörleri çalışmamızda görünmemektedir.
Türkiye'de baş boyun kanserleri içinde en sık görülen kanser, larenks kanseridir ve baş boyun kanserleri daha çok erkeklerde görülmektedir. Türkiye'deki larenks kanseri insidans oranı $\% 2,7$ mortalite oranı $\% 1,9$, ağız boşluğu kanseri insidans oranı \%1,7, mortalite oranı $\% 1$, nazofarenks kanseri insidans oranı $\% 0,6$, mortalite oranı $\% 0,5$ iken, hipofarenks kanserinde insidans $\% 0,3$ mortalite oranı $\% 0,3$ olarak bildirilmektedir [3]. Bizim çalışmamızda da baş boyun kanserlerindede en sık görülen kanser larenks kanseridir ve baş boyun kanserleri daha çok erkeklerde görülmüştür.

Dünya'da erkeklerde görülen en sık kanser türleri sırasıyla Akciğer, sindirim sistemi ve prostat olurken, oral kavite kanserleri 8., larenks kanserleri 11., diğer farenks kanserleri 14. sıradadır. Kadınlarda ise en sık görülen kanserler meme, sindirim sistemi ve serviks olurken, oral kavite kanserleri 13. sırada görülmektedir [6]. Dünya'da ve Türkiye'de baş boyun kanserlerinin insidans hızları Tablo 4'te karşılaştırılmıştır. Baş ve boyun kanserlerinin içerisinde dünya'da en sık görülen alt tür, tüm kanserler içinde $\% 2,1$ pay ile oral kavite ve dudak kanserleri iken yurdumuzda en sık görülen alt tür ise tüm kanserler içerisinde $\% 1,9$ pay ile larenks kanseridir. Hastalık erkeklerde kadınlara göre 
Tablo 4. Çeşitli baş boyun kanseri tipleri insidans hızları Türkiye ve Dünya karşılaştırılması.

\begin{tabular}{lllll}
\hline & \multicolumn{2}{l}{2018 Globalscan [2]. } & \multicolumn{2}{l}{2014 Türkiye Halk Sağlığı Kurumu [3]. } \\
& Erkek & Kadın & Erkek & Kadın \\
\hline Dudak ve Oral Kavite & 5,8 & 2,3 & 7 & 2,8 \\
Tükrük bezleri & 0,7 & 0,5 & 0,5 & 0,4 \\
Nazofarenks & 2,2 & 0,8 & 1,2 & 0,4 \\
Orofarenks & 1,8 & 0,4 & 1,2 & 0,4 \\
Hipofarenks & 1,6 & 0,3 & 0,3 & 0,2 \\
Larenks & 3,6 & 0,5 & 6,2 & 0,5 \\
Ösafagus & 9,3 & 3,5 & 2 & 1 \\
Beyin sinir sistemi & 3,9 & 3,1 & 5,2 & 4,1 \\
Troid & 1,5 & 4,7 & 5,5 & 20,7 \\
Lenfoma & 7,8 & 5,5 & 9 & 6,2 \\
\hline
\end{tabular}

Farklı gruplamalar nedeniyle bazı gruplar birleştirilmiştir. Bu yüzden sayılar yaklaşık olabilir.

daha sık görülür. Dünya genelinde erkek/kadın oranı 3/1, ülkemizde ise 4,4/1'dir [2,3].

2013 yılında Sivas Numune Hastanesi'nde 82 hasta üzerinde yapılan çalışmada en genç hastaların nazofarenks, parahipofarenks ve paranazal sinüs tümörü olan hastalar olduğu bildirilmiştir [7]. Bizim çalışmamızda paratiroid ve beyin tümörleri(Baş boyun uzanımı olan) en genç hasta grubu olarak saptanmıştır.

The Agency for Healthcare Research and Quality (AHRQ) yaptığı çalışmada kanser hastalığının tedavisi için Amerika Birleşik Devletleri'nde 2011 yılında harcanan paranın 88,8 milyar dolar oarak hesaplamıştır. Bu paranın \%35'i yatarak tedavi masraflarına aittir [8]. Ülkemizde ne yazık ki bu tür kapsamlı çalışma yapılmamıştır. Ama tahminen yıllık kanser tedavi masrafları 2,3 milyar Euro civarındadır [9]. Pamukkale Üniversitesi'ne başvuran hastalar ortalama 8,47 gün yatarak tedavi görmüşlerdir. Toplam tahsis edilen yatak gün sayısı 13.865 'dir. Onbeş yataklı bir klinik olduğumuz düşünülürse 10 yılda kliniğimizin yatak kaynaklarının $\% 25$ i baş boyun tümörlü hastalara tahsis edilmiştir. Bu hesaba onkoloji yatışları, bakım yatışları dahil değildir.

Kanser istatistiklerine göre Amerika'da 1991 yılından beri kanserden ölümler azalmaktadır. Fakat sosyoekonomik şartlar bu düşüşün toplumun bütün kesimlerine eşit olarak dağılmasını engellemektedir [10]. Daha iyi teşhis ve tedavi olanakları yaygınlaştıkça toplumun bütün kesimleri bu iyi gidişten yararlanacaktır. Tabi ki bu şart ancak sosyal güvenlik sisteminin yatırımları ile sağlanabilir. Bu yatırımların doğru ve yerinde yapılabilmesi için de istatistiklerin yapılması ve yayınlanması önemli bir altyapı oluşturur.

Çalışmanın sınırlılıklarından biri sadece Kulak Burun Boğaz kliniği kayıtlarından yararlanılması bu yüzden deri ve tiroid tümörlerinin istatistik dışı kalmasıdır. İkinci unsur hastaların maliyet unsurlarının değerlendirmeye alınmamasıdır. Sadece yatak kullanımı ve insan kaynakları açısından değerlendirmiştir. Diğer bir konu ülkemizde sağlık ekonomisi çalışmalarının baş boyun tümörlerine henüz odaklanmamış olmasıdır. Bu yüzden bölgesel ve ulusal düzeyde kaynak kullanımı karşılaştırması yapmak mümkün olmamıştır.

Sonuç olarak, bu çalışmada Denizli bölgesindeki baş boyun tümörlerinin durumu tespit edilmiş ve Kulak Burun Boğaz Anabilim Dalı'nın yatak ve işgücü açısından kaynaklarının $\% 25$ 'ini bu hastalar için kullandığını görülmüştür. Bu durumun insan gücü eğitimini ve yatırımları yönlendirebilmesi için öncelikle karşılaştırma yapılabilecek bölgesel ve ulusal düzeyde konularına göre ayrılmış epidemiyolojik ve ekonomik çalışmaların yapılmasına intiyaç vardır. Bu şekilde sağlık alanında daha iyi planlama yapılabilecektir. 
Çıkar ilişkisi: Yazarlar çıkar ilişkisi olmadığını beyan eder.

\section{Kaynaklar}

1. Bray F, Ferlay J, Soerjomataram I, Siegel RL, Torre LA, Jemal A. Global cancer statistics 2018: GLOBOCAN estimates of incidence and mortality worldwide for 36 cancers in 185 countries. CA Cancer J Clin 2018;68:394424. http://dx.doi.org/10.3322/caac.21492

2. International agency for research on cancer, GLOBOCAN 2018 accessed via Global Cancer Observatory.

3. Halk Sağlığı Genel Müdürlüğü Türkiye Kanser istatistikleri 2014. https://hsgm.saglik.gov.tr/depo/ birimler/kanser-db/istatistik/2014-RAPOR._uzuuun.pdf

4. Economopoulou P, Psyrri A. Epidemiology, risk factors and pathogenesis of squamous cell tumours. In Licitra L, Karamousiz MV(eds), Head and Neck Cancers: essentials for clinicians. https://oncologypro.esmo. org/content/download/113133/1971849/file/2017ESMO-Essentials-for-Clinicians-Head-Neck-CancersChapter-1.pdf

5. Başak K, Sağlam Y, Yıldız AG, et al. Profile of head and neck cancers in Dr. Lütfi Kırdar Kartal Educational and Research Hospital. Turk Patoloji Derg 2015;31:119-25. http://dx.doi.org/10.5146/tjpath.2014.01294

6. GLOBOCAN 2000: Cancer Incidence, mortality and prevalence worldwide the global burden of cancerIARC Publications. https://publications.iarc.fr/_ publications/media/download/4096/8d2ac4c0f150ba4 5bf63edb930660cfbed158484.pdf

7. Atasever Akkaş E, Yücel B, Kılıçkap S, Akgül Babacan $\mathrm{N}$, Altuntaş E. Baş boyun kanserli hastalarda tedavi sonuçları ve prognostik faktörler. Cumhuriyet Tıp Derg 2013;35:75-66. http://dx.doi.org/10.7197/13050028.1744

8. American Cancer Society. Cancer facts and figures-2015. Atlanta: American Cancer Society, 2015. https://www.cancer.org/content/dam/cancer-org/ research/cancer-facts-and-statistics/annual-cancerfacts-and-figures/2015/cancer-facts-and-figures-2015. pdf)

9. Karacan R, Kılıçkan Z. Türkiye'de kanser hastalığının bütçeye getirdiği yük bakımından tarama ve tedavi edici sağık harcamalarının karşılaştırılması. Finans Politik \& Ekonomik Yorumlar 2016;53:45-52.

10. Siegel RL, Miller KD, Jemal A. Cancer statistics, 2019. CA Cancer J Clin 2019;69:7-34. http://dx.doi. org/10.3322/caac. 21551

Etik kurul izni, Pamukkale Üniversitesi Girişimsel Olmayan Klinik Çalışmalar Etik Kurul'undan alınmıştır (60116787-020/45983). 